Article

\title{
Extrusion of Porous Protein-Based Polymers and Their Liquid Absorption Characteristics
}

\author{
Antonio J. Capezza ${ }^{1,2, *} \mathbb{E}$, Eva Robert ${ }^{1}$, Malin Lundman ${ }^{3}$, William R. Newson ${ }^{2}$, \\ Eva Johansson ${ }^{2}\left(\mathbb{D}\right.$, Mikael S. Hedenqvist ${ }^{1}(\mathbb{D})$ and Richard T. Olsson ${ }^{1, *}$ \\ 1 Fibre and Polymer Technology, KTH Royal Institute of Technology, Teknikringen 56, SE-100 44 Stockholm, \\ Sweden; erobert@kth.se (E.R.); mikaelhe@kth.se (M.S.H.) \\ 2 Department of Plant Breeding, SLU Swedish University of Agricultural Sciences, BOX 101, SE-230 53 Alnarp, \\ Sweden; bill.newson@slu.se (W.R.N.); eva.johansson@slu.se (E.J.) \\ 3 Essity Hygiene and Health AB, SE-405 03 Gothenburg, Sweden; malin.lundman@essity.com \\ * Correspondence: ajcv@kth.se (A.J.C.); rols@kth.se (R.T.O.); Tel.: +46-762-301654 (A.J.C.); \\ $+46-732-701868$ (R.T.O.)
}

Received: 30 January 2020; Accepted: 13 February 2020; Published: 16 February 2020

check for updates

\begin{abstract}
The production of porous wheat gluten (WG) absorbent materials by means of extrusion processing is presented for the future development of sustainable superabsorbent polymers (SAPs). Different temperatures, formulations, and WG compositions were used to determine a useful protocol that provides the best combination of porosity and water swelling properties. The most optimal formulation was based on $50 \mathrm{wt} . \% \mathrm{WG}$ in water that was processed at $80{ }^{\circ} \mathrm{C}$ as a mixture, which provided a porous core structure with a denser outer shell. As a green foaming agent, food-grade sodium bicarbonate was added during the processing, which allowed the formation of a more open porous material. This extruded WG material was able to swell $280 \%$ in water and, due to the open-cell structure, $28 \%$ with non-polar limonene. The results are paving the way towards production of porous bio macromolecular structures with high polar/non-polar liquid uptake, using extrusion as a solvent free and energy efficient production technique without toxic reagents.
\end{abstract}

Keywords: wheat gluten; protein; extrusion; sustainability; absorbents; porosity; circularity

\section{Introduction}

Porous materials from petroleum-based polymers (e.g., polystyrene and polyurethane) are widely used to produce plastic foam materials for various engineering areas [1-4]. Here, interconnected porosity is of interest and useful in fluid absorption applications relying on absorption by means of capillary action [5-8]. Absorption by means of capillary action has been of particular interest over the last few decades due to the increasing demand for daily-care products, partly related to worldwide population growth [9-12]. However, the common use of fossil-based polymers in the hygiene industry is well known and highlights the need for finding more sustainable bio-based alternative materials [11,13-15]. Recent studies have shown that foam structures can be effectively prepared utilizing macromolecules from nature, such as polysaccharides and/or proteins [16-18]. These absorbent materials have most frequently been obtained through lyophilization where the material is frozen and the water crystals being templates are sublimated in order to generate porosity $[19,20]$. Hemicellulose- and protein-based foams have shown a liquid absorption capacity of 12.5 and $32 \mathrm{~g} / \mathrm{g}$, respectively, demonstrating their potential to replace their petroleum-based counterparts [20-22]. The absorption capacities for such bio-based foams have been within the range of those for fossil-based absorbent polymers $(>10 \mathrm{~g} / \mathrm{g})$ [23].

While lyophilization is the most common method for producing bio-based porous materials in the laboratory, other techniques have been reported, including more expensive super critical drying 
or complex Pickering emulsions using nanoparticles to stabilize the air-liquid interphase during the foam preparation [24-26]. The two techniques can be used to create pores with a size of the order of $20 \mu \mathrm{m}$ and $10 \mathrm{~nm}$, respectively [27,28], but, similarly with lyophilization, the techniques suffer from high cost and intense energy use in any industrial scale production [29,30]. Interestingly, it has been shown that wheat gluten (WG) proteins demonstrate such cohesive viscoelastic properties that neither of the above cost-energy expensive techniques is required for the production of porous materials with high liquid absorption ( $>500 \%$ in water) [31]. Gluten is therefore a particularly interesting candidate for the production of sustainable superabsorbent polymers (SAPs), not the least because WG is an agricultural industry co-product not requiring expensive and energy-demanding techniques [19,32-34]. Addressing the scalability issues towards production for the daily-care product market within a circular economy while taking advantage of the added value of WG as a raw material requires, however, attention to how the WG materials can be processed using large-scale foam production techniques $[11,35]$. Here, the most common commercial processing by far is extrusion [36,37], making it the most attractive technique for processing bio-based macromolecules and/or proteins for use as porous materials [11].

In this article, we report the extrusion of porous WG materials for the development of future scalable protocols targeting sustainable superabsorbent materials for use in daily-care product applications. Extrusion was performed on a $50 \mathrm{wt}$.\% aqueous WG mixture and the most optimal conditions were established in the temperature window from $80{ }^{\circ} \mathrm{C}$ to $120^{\circ} \mathrm{C}$, resulting in extrudates with pore sizes ranging from 65 to $116 \mu \mathrm{m}$, composed of both open and closed pores. The open porosity, coupled with the high swelling properties of the WG, allowed a rapid liquid absorption with up to $280 \%$ weight increase in water and approximately 30\% weight increase in non-polar limonene. In the developed protocol, water was used as a dispersant/blowing agent, glycerol as a processing aid, and sodium bicarbonate $\left(\mathrm{NaHCO}_{3}\right)$ as a chemical blowing agent, which are all environmentally friendly chemicals. The results demonstrate the possibilities of using WG as a raw material for the production of porous structures with a high swelling capacity. WG is a competitive bio-based polymer that from life cycle assessment studies has shown promising environmental characteristics that are better than PLA, for example [35].

\section{Materials and Methods}

Wheat gluten (WG) concentrate powder was provided by Lantmännen Reppe AB, Lidköping, Sweden. The WG was obtained as a product-stream from industrial wheat starch extraction with a reported protein content of $86.3 \pm 0.3$ (Dumas method, NMKL 6:2003, USA, nitrogen/protein conversion factor $\mathrm{N} \times 6.25)$. The fat and ash contents of the received WG powder were $0.9 \% \pm 0.1 \%$ and $0.8 \% \pm 0.1 \%$, respectively (2009/152/EU mod and NMKL 173). Glycerol (ACS reagent, $>99.5 \%$ ) was purchased from Sigma-Aldrich (Stockholm, Sweden). Sodium bicarbonate (ACS reagent, >99.7\%) was purchased from Sigma-Aldrich (Stockholm, Sweden). The defibrinated sheep blood was provided by Disease Vector Group, Swedish University of Agricultural Sciences, Alnarp, Sweden. The extruder used was a single screw Axon AB (type BX18) having 5 heating/cooling zones along the barrel and die (4 equally distributed on the barrel and 1 on the die). The extruder was equipped with a screw having a length $375 \mathrm{~mm}$ and a diameter of $15 \mathrm{~mm}(\mathrm{~L} / \mathrm{D}=25)$, with a compression ratio of 2.57 (feeding zone and meeting zone depth of 3 and $1 \mathrm{~mm}$, respectively).

\subsection{Extrusion of the WG/Water Formulations}

A $100 \mathrm{~g}$ portion of WG powder was gradually added to a beaker containing $100 \mathrm{~mL} \mathrm{MilliQ}$ water (MQw), pre-adjusted to $\mathrm{pH} 11$ (using $1 \mathrm{M} \mathrm{NaOH})$. Other WG contents were also tested, but the 1:1 gluten:water mass ratio yielded the highest WG content while having good cohesive/extrusion properties. A slow addition of the WG aimed to avoid the excessive formation of granules. The $\mathrm{pH}$ of the mixture was continuously monitored by using $\mathrm{pH}$-meter paper stripes, and corrected to 11 when needed. The $\mathrm{pH}$ was kept at 11 to favor WG protein denaturation and expose the protein functional groups. For the initial mixing, magnetic stirring was used, but as the mixture became too viscous (after 
approximately the addition of $30 \mathrm{~g}$ of $\mathrm{WG})$, manual mixing was performed. The total mixing time for the 1:1 WG:water mix formation was approximately $15 \mathrm{~min}$. Long mixing times should be avoided as it can induce alkaline crosslinking in the WG [38].

The WG mix (with solidity resembling a dough for breadmaking) was immediately transferred to the Axon $\mathrm{AB}$ (type BX18) extruder. The temperatures used for the extrusion were $20-50-60-70-80^{\circ} \mathrm{C}$ (barrel-barrel-barrel-barrel-die) (Low Temperature profile (LT)) and 20-90-100-110 - $120^{\circ} \mathrm{C}$ (High Temperature profile (HT)). The die was circular having a diameter of $6 \mathrm{~mm}$. The screw speed was always set at $20 \mathrm{rpm}$. The extruded WG strands were placed in a forced-air oven at $40{ }^{\circ} \mathrm{C}$ for $24 \mathrm{~h}$ to dry the materials (post-extrusion). Thereafter, the materials were kept inside silica-containing desiccators at least 1 week prior to any test. For comparison, pieces of unextruded WG/water mix were placed into cubic molds $\left(1 \mathrm{~cm}^{3}\right)$ and then frozen at $-25^{\circ} \mathrm{C}$ for $24 \mathrm{~h}$. Thereafter, the frozen cubes were lyophilized for $48 \mathrm{~h}$ and stored in the silica-containing desiccator. This sample was named WG(f).

\subsection{Extrusion of WG/Water/Glycerol}

The sample preparation was the same as described in Section 2.1, with the only difference being that $5 \mathrm{wt} . \%$ of glycerol was added to the pre-adjusted $\mathrm{pH} 11 \mathrm{MQw}$ before the gluten addition. This sample was also extruded using the extrusion profiles described in 2.1, that is, the LT (Low Temperature, $20-50-60-70-80^{\circ} \mathrm{C}$ ) and the HT (High Temperature, $20-90-100-110-120^{\circ} \mathrm{C}$ ) profiles. These samples were named WG 5G LT and WG 5G HT.

\subsection{Extrusion of WG/Water/Sodium Bicarbonate}

The sample preparation was the same as described in Section 2.1. However, after the mixing of WG with the water pre-adjusted to $\mathrm{pH} 11,5 \mathrm{~g}$ of $\mathrm{NaHCO}_{3} / 100 \mathrm{~g} \mathrm{WG}$ were added to the mixture and thoroughly mixed before the extrusion. These samples were named WG 5S LT and WG 5S HT.

\subsection{Extrusion of WG/Water/Glycerol/Sodium Bicarbonate}

The sample preparation was the same as described in Section 2.2. However, after the mixing of WG with water, pre-adjusted to $\mathrm{pH} 11$ (containing $5 \mathrm{wt} . \%$ of glycerol), $5 \mathrm{~g}$ of $\mathrm{NaHCO}_{3} / 100 \mathrm{~g} \mathrm{WG}$ were added to the dough and thoroughly mixed before the extrusion. These samples were named WG 5G5S LT and WG 5G5S HT. A summary of the different sample names and formulations is described in Table 1.

Table 1. Sample formulations and the extrusion parameters used. ${ }^{1}$

\begin{tabular}{|c|c|c|c|c|}
\hline Sample Name & WG (wt.\%) & Water (wt.\%) & Glycerol (wt.\%) & $\begin{array}{c}\text { Sodium } \\
\text { Bicarbonate } \\
\text { (g/100g WG) }\end{array}$ \\
\hline WG LT & 50 & 50 & & \\
\hline WG HT & 50 & 50 & & \\
\hline WG 5G LT & 50 & 45 & 5 & \\
\hline WG 5G HT & 50 & 45 & 5 & \\
\hline WG 5S LT & 50 & 50 & & 5 \\
\hline WG 5S HT & 50 & 50 & & 5 \\
\hline WG 5G5S LT & 50 & 45 & 5 & 5 \\
\hline WG 5G5S HT & 50 & 45 & 5 & 5 \\
\hline
\end{tabular}




\subsection{Swelling}

The swelling capacity (SC) of the samples was determined by completely immersing pieces of the samples in MQw or limonene. The immersion times were 10, 30, and $1440 \mathrm{~min}(24 \mathrm{~h})$. After removing the samples from the liquid, they were placed on a tissue paper for $10 \mathrm{~s}$ to remove the excess liquid. The swelling was calculated according to Equation (1), and the results are reported as averages of triplicates, with standard deviations. Parts of some dried extruded WG samples were ground in a mortar until a powder was obtained. This was made to assess the free liquid swelling of the samples (free swelling capacity (FSC)) and to eliminate the effect of having closed cells in the materials. The FSC was calculated using the Nonwovens Standard Procedure (NWSP 240.0.R2) "tea-bag" [39,40]. Briefly, approximately $460 \mathrm{mg}$ of extruded dry materials was added to a nonwoven fabric bag having a dimension of $40 \times 60 \mathrm{~mm}^{2}$ (mesh $=400$ ). The bag containing the material was hooked on a rod and immersed in a beaker containing MQw. The immersion time was the same as before. After the immersion, the bag was hung for $10 \mathrm{~s}$ outside the liquid and then placed on a tissue paper for $10 \mathrm{~s}$ to remove unabsorbed water. Three empty bags were handled identically to obtain an average correction factor $\left(\mathrm{W}_{\mathrm{b}}\right)$ using Equation (2). The FSC was estimated using Equation (3) and the results are reported as the average of triplicates.

$$
\begin{gathered}
\mathrm{SC}=\left(\mathrm{W}_{2}-\mathrm{W}_{1}\right) / \mathrm{W}_{1} \\
\mathrm{~W}_{\mathrm{b}}=\mathrm{W}_{\mathrm{s}} / \mathrm{W} \\
\mathrm{FSC}=\left(\left[\mathrm{W}_{\mathrm{i}}-\left(\mathrm{W}_{0} \times \mathrm{W}_{\mathrm{b}}\right)\right]-\mathrm{W}_{\mathrm{d}}\right) / \mathrm{W}_{\mathrm{d}}
\end{gathered}
$$

$W_{1}$ is the dry weight of the extruded specimen, and $W_{2}$ is the swollen weight of the specimen. $\mathrm{W}_{\mathrm{s}}$ and $\mathrm{W}$ are the weights of the wet and dry blank bags, respectively. $\mathrm{W}_{\mathrm{i}}$ is the weight of the swollen material, $\mathrm{W}_{0}$ the weight of the dry bag used, and $\mathrm{W}_{\mathrm{d}}$ the weight of the added dry ground sample.

An additional absorption test using defibrinated sheep blood was performed on some samples [39]. The sheep blood absorption was used to show the swelling capacity of other liquids important for the daily-care product industry. The immersion time was always $30 \mathrm{~min}$ and the swelling was calculated using Equation (1), and the results are reported as the average of duplicates.

\subsection{Density Measurements}

The density was calculated using two methods. The apparent density $\left(\rho_{\mathrm{a}}\right)$ was calculated using the weight of the dry samples (using a Mettler Toledo AL104 balance) divided by its volume (assuming a cylindrical shape), and the Archimedes principle.

The weights of the samples were measured in air and in n-heptane, and the Archimedes density $(\rho)$ was calculated using Equation (4) as follows:

$$
\rho=(\mathrm{A} /(\mathrm{A}-\mathrm{B})) \cdots\left(\rho_{\mathrm{o}}-\rho_{1}\right)+\rho_{1}
$$

where $A$ and $B$ are the weight of the sample in air and n-heptane, respectively, $\rho_{o}$ is the density of n-heptane $\left(0.6838 \mathrm{~g} / \mathrm{cm}^{3}\right)$, and $\rho_{1}$ is the density of air $\left(0.0012 \mathrm{~g} / \mathrm{cm}^{3}\right)$. The porosity was estimated by using Equation (5) and the apparent density of each material $\left(\rho_{a}\right)$ and taking the raw WG powder density as $1300 \mathrm{~kg} / \mathrm{m}^{3}$ [31]. The closed cell porosity was estimated by means of Equation (6), using the density of the raw WG powder $\left(1278 \pm 49 \mathrm{~kg} / \mathrm{m}^{3}\right)$ and the density of each sample $(\rho)$ calculated from the Archimedes method (Equation (4)). The lower density of the WG powder obtained by the Archimedes method is a consequence of the method not considering air trapped in the particles.

$$
\begin{gathered}
\text { Porosity }(\%)=\left[1-\left(\rho_{\mathrm{a}} / 1300\right)\right] \cdots 100 \\
\text { Closed cell porosity }(\%)=[1-(\rho / 1278)] \cdots 100
\end{gathered}
$$




\subsection{Fourier-Transform Infrared Spectroscopy (FTIR)}

The effect of the extrusion processing on the WG was studied using FTIR. The FTIR spectrum was obtained using a PerkinElmer Spectrum 100 coupled to a Golden Gate unit (Single-reflection ATR, Graseby Specac Ltd, Kent, England). A triglycine sulphate (TGS) detector was used with a resolution of $4.0 \mathrm{~cm}^{-1}$, and 32 consecutive scans were performed per sample. The samples were dried in a desiccator over silica for 1 week before the runs. A peak deconvolution was performed as reported by Cho et al. [41] using the PerkinElmer Spectrum software (version 10.5.1 (2015)) with an enhancement factor $(\gamma)$ of 2 and a smoothing filter of $70 \%$.

\subsection{Scanning Electron Microscopy (SEM)}

The morphology of the different samples was investigated using a Hitachi TM-1000 tabletop SEM (Tokyo, Japan) (10 kV voltage, $6 \mathrm{~mm}$ working distance, backscattering mode). The extruded samples were immersed in liquid nitrogen for $5 \mathrm{~min}$ and then fractured. The cryo-fractured cross-sections of the samples were placed on a conductive carbon tape. To evaluate the structure of the samples after being immersed in MQw for $24 \mathrm{~h}$, the extruded swollen samples were frozen at $-25^{\circ} \mathrm{C}$ during $24 \mathrm{~h}$ and then lyophilized for $48 \mathrm{~h}$. The lyophilized samples were immersed in liquid nitrogen and cryo-fractured. The surface morphology was analyzed using a Hitachi S-4800 field emission scanning electron microscope (FE-SEM). A voltage of $3 \mathrm{kV}$ and a current of $10 \mu \mathrm{A}$ were used. The lyophilized materials were sputtered with a palladium/platinum ( $\mathrm{Pt} / \mathrm{Pd}$ ) target in an Agar High Resolution Sputter Coater (model 208RH). The sputtering time for all samples was $45 \mathrm{~s}$ proving an estimated conductive layer of 1-2 nm. The pore size of the extrudates was estimated using Image ${ }^{\circledR}{ }^{[42]}$, taking at least 50 measurements and reporting the average and standard deviation. The pore size measurements were made using $500 \times$ images, and when no porosity was observed at this magnification, the sample was considered non-porous.

\subsection{Thermal Gravimetric Analysis (TGA)}

The thermal stability of the extruded WG samples was studied using a Mettler-Toledo TGA/SDTA851 instrument (Leicester, England). An amount of $5.0 \pm 0.03 \mathrm{mg}$ of the ground material was put in $70 \mu \mathrm{L}$ alumina crucibles. The method consisted of a drying step of $10 \mathrm{~min}$ at $50^{\circ} \mathrm{C}$ followed by heating from $50{ }^{\circ} \mathrm{C}$ to $800{ }^{\circ} \mathrm{C}\left(10^{\circ} \mathrm{C} / \mathrm{min}\right)$. A nitrogen flow of $50 \mathrm{~mL} / \mathrm{min}$ was used during the tests.

\section{Results and Discussion}

\subsection{Physical Characteristics}

Figure 1a shows that the extrusion of WG at low temperature (WG LT) provided a porous structure inside the sample and a denser structure as the outer shell. The same porous characteristics were observed for the WG sample containing $5 \mathrm{wt} . \%$ glycerol, also extruded at low temperature (WG 5G LT), Figure 1c. Both WG LT and WG 5G LT could be extruded with essentially a cylindrical shape of the extrudate and a pore size of $85 \mu \mathrm{m}$ and $65 \mu \mathrm{m}$, respectively. The diameter of the inner porous core of the WG LT sample was approximately $2 \mathrm{~mm}$, whereas it was $2.5 \mathrm{~mm}$ for WG 5G LT. Glycerol, a known protein plasticizer and a processing aid, made the WG more stretchable and allowed more vapor-generated expansion at the exit of the die before the gases exited the extrudate surface. However, when these samples were extruded at higher temperatures (here, $120^{\circ} \mathrm{C}$ at the metering zone), the porosity in the core, previously obtained at $80^{\circ} \mathrm{C}$, was absent (see Figure $1 \mathrm{~b}, \mathrm{~d}$ ). The cylinder-like shape was also obtained for the WG HT and WG 5G HT samples, but a temperature above $100{ }^{\circ} \mathrm{C}$ was previously reported to lead to extensive crosslinking with disulphide (-S-S-) bonds in WG materials. Therefore, the high temperature and crosslinked WG matrix when extruded at high temperature could hinder the expansion generated by the water vapor in the WG extrudate when exiting the extruder. This could also explain the absence of the inner porous core in WG HT and 
WG 5G HT. In addition, the HT generated shorter and more discontinuous products due to pressure variations at the extruder die, thereby affecting the production rate for this protocol (see Table 1).

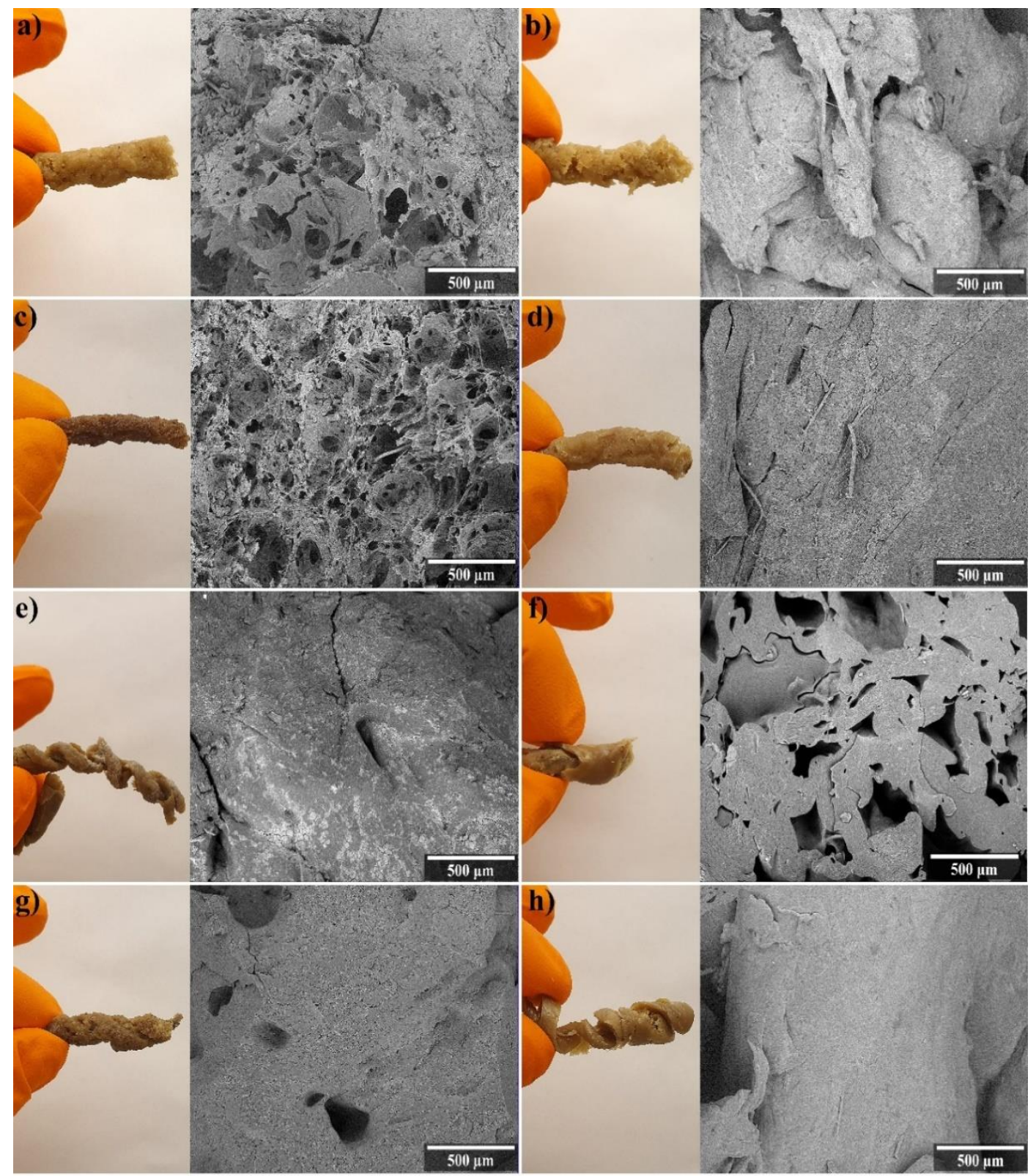

Figure 1. Images of the WG extrudates after drying and their respective SEM cross-sections. The panels show (a) WG LT, (b) WG HT, (c) WG 5G LT, (d) WG 5G HT, (e) WG 5S LT, (f) WG 5S HT, (g) WG 5G5S LT, and (h) WG 5G5S HT.

Figure 1e shows that the addition of sodium bicarbonate $\left(\mathrm{NaHCO}_{3}\right)$ to the $\mathrm{WG}$ aqueous mixture (here, WG 5S LT) did not lead to any porosity at low extrusion temperatures. In addition, the cylindrical shape was lost (Figure 1e), and a helical shape originally from the flow inside the extruder barrel was obtained. The effect is a consequence of not having a "breaker plate" or a coarse screen between the barrel and the die. The high magnification images of WG 5S LT revealed the presence of aggregates, which are likely WG aggregates formed as the result of protein tendons stretched across the bubbles before they collapsed and then relaxed into spheres (Figure S1a). However, contrary to WG HT and WG 5G HT, the WG 5S HT sample showed numerous irregular open pores of approximately $300 \mu \mathrm{m}$ in size (Figure 1f). When observed at higher magnifications, the WG 5S HT sample had a structure 
that suggests that the micropores collapsed when exiting the extruder (Figure S1b). The now formed irregular open pores in WG 5S HT can be the result of the effective decomposition of the $\mathrm{NaHCO}_{3}$ forming $\mathrm{CO}_{2}(\mathrm{~g})$. The $\mathrm{CO}_{2}(\mathrm{~g})$ formation from $\mathrm{NaHCO}_{3}$ is indeed more favored at temperatures above $115^{\circ} \mathrm{C}$ [43], explaining the increased pore expansion obtained for WG 5S HT compared to WG 5S LT.

The combination of glycerol and $\mathrm{NaHCO}_{3}$ in samples extruded at low temperatures (WG 5G5S LT, Figure 1g) resulted in irregular cylindrically shaped extrudates with occasionally observed $300 \mu \mathrm{m}$ large pores. The high magnification of this sample reveals a similar collapsed porous structure as that for WG 5S HT, but with the presence of several WG aggregates (Figure S2a) similar to the ones observed on the WG 5S LT sample (Figure 1e). The WG 5G5S HT sample (Figure 1h) had a helical shape similar to WG 5S LT, and a dense structure even on a microscale (Figure S2b). Therefore, the combination of glycerol and $\mathrm{NaHCO}_{3}$ favored the formation of a more regular extrudate (compare WG 5S LT and WG 5G5S LT, Figure 1), while at high temperatures the structure obtained was dense. The more regular inner core porosity and cylindrical shape obtained for WG 5G LT suggest that the addition of only glycerol provides a greater water vapor-generated expansion at the extruder die. Likewise, when an open porosity is desired, the addition of $\mathrm{NaHCO}_{3}$ and the use of a high temperature is the best combination. The results, however, pave the way for future work on glycerol/ $\mathrm{NaHCO}_{3}$ mass ratio optimization and the use of new bio-based foaming agents in order to optimize the formation of more regular and continuous extrudates having mainly an open-pore structure.

Using the apparent density of the cylinders, it was estimated that the samples WG LT and WG 5 G LT had a porosity of $36 \%$ and $16 \%$, respectively (Table 2). Due to the irregular shape of some samples, the apparent density was not calculated (not measured (NM), Table 2). The above-mentioned samples also resulted in the presence of closed pores (i.e., 7\% for WG LT and 3\% for WG 5G LT), according to the Archimedes density results. This agrees with the SEM images, showing a porous core and a denser skin layer in these samples (Figure 1a-c). However, the WG 5S HT sample resulted in the highest closed-pore content (12\%, Table 2). This shows that not all the large pores observed in the SEM micrographs were accessible for the liquid penetration (Figure 1f). The porosity of WG LT shows that by the use of only water together with the WG in the extrusion, approximately $48 \%$ of the porosity of the lyophilized foam (WG(f)) can be obtained (Table 2). Moreover, when sodium bicarbonate was used in the formulations (WG 5 S HT), the porosity reached $53 \%$, representing $73 \%$ of the porosity of WG(f) (Table 2). Although the pore size of the WG 5S HT sample was approximately four times larger than that of $\mathrm{WG}(\mathrm{f})$, the results show the potential of using $\mathrm{NaHCO}_{3}$ as foaming agent in the gluten formulation in combination with high temperatures. The core porosity obtained in WG $5 \mathrm{~S}$ HT (i.e., using the continuous extrusion process) also represents approximately $50 \%$ of the porosity obtained in our previous work by the utilization of a non-continuous technique to produce WG porous structures [31]. Briefly, WG was mixed with water and glutaraldehyde, then the water was decanted from the mixture and the porous material was dried for $24 \mathrm{~h}$ [31]. At high magnifications (Figures S1 and S2) of WG 5S LT, WG 5S HT, and WG 5G5S LT, a microporosity with a size of $3 \pm 2 \mu \mathrm{m}, 7 \pm 4 \mu \mathrm{m}$, and $4 \pm 3 \mu \mathrm{m}$, respectively, was observed. All samples had high pore size variation (both large and small pores were considered for the calculations, Figure 1 and Table 2). Generally, the closed-pore fraction was a low percentage of the total volume, being the highest for WG 5S HT (12\%) and lowest for WG 5G HT (1\%). 
Table 2. Physical properties of the different samples.

\begin{tabular}{|c|c|c|c|c|c|}
\hline Sample Name & $\begin{array}{l}\text { Apparent } \\
\text { Density } \\
\left(\mathrm{kg} / \mathrm{m}^{3}\right)\end{array}$ & $\begin{array}{c}\text { Archimedes } \\
\text { Density } \\
\left(\mathrm{kg} / \mathrm{m}^{3}\right)\end{array}$ & $\begin{array}{c}\text { Porosity with } \\
\text { Density (\%) }\end{array}$ & $\begin{array}{c}\text { Closed Cells } \\
(\%)\end{array}$ & Pore Size $(\mu \mathrm{m})^{1}$ \\
\hline WG(f) & $351 \pm 29$ & NM & 73 & NM & $27 \pm 13$ \\
\hline WG LT & $835 \pm 89$ & $1193 \pm 12$ & 36 & 7 & $85 \pm 67$ \\
\hline WG HT & NM & $1287 \pm 9$ & NM & 0 & NP \\
\hline WG 5G LT & $1093 \pm 140$ & $1246 \pm 3$ & 16 & 3 & $65 \pm 50$ \\
\hline WG 5G HT & $665 \pm 68$ & $1263 \pm 15$ & 49 & 1 & NP \\
\hline WG 5S LT & NM & $1280 \pm 18$ & NM & 0 & NP \\
\hline WG 5S HT & $612 \pm 83$ & $1150 \pm 34$ & 53 & 12 & $116 \pm 138$ \\
\hline WG 5G5S LT & NM & $1223 \pm 25$ & NM & 4 & $\mathrm{NP}^{2}$ \\
\hline WG 5G5S HT & NM & $1293 \pm 8$ & NM & 0 & NP \\
\hline
\end{tabular}

The density of the raw WG powder according to Archimedes was $1278 \pm 49 \mathrm{~kg} / \mathrm{m}^{3}$ and the reported density was $1300 \mathrm{~kg} / \mathrm{m}^{3}$. NM: not measured. ${ }^{1}$ The pore size was measured on the $500 \times$ SEM images. ${ }^{2}$ If no porosity was possible to observe at this magnification, it was considered as a non-porous sample (NP).

\subsection{Swelling}

All samples showed water swelling scenarios demonstrating the following characteristics; reaching a first plateau within 10-12 min, which remained stable for approximately $20 \mathrm{~min}$, followed by an increase after $30 \mathrm{~min}$ (Figure 2a). This behavior was previously observed for WG-superabsorbent materials and was due to the plasticization effect of water on the gluten protein [21]. The highest water swelling was obtained for WG 5S HT after $30 \mathrm{~min}$ and $24 \mathrm{~h}, 100 \%$ and 290\%, respectively (Figure 2b). This was due to the large open pores observed in the sample (Figure 1f), which allowed the water to spread out easily and interact with a greater WG surface. Note that for the same sample at low extrusion temperatures (WG 5S LT), the water swelling was $225 \%$, also demonstrating the effect of the large pores. With $250 \%$ water uptake ( $24 \mathrm{~h}$, Figure $2 \mathrm{a}$ ), the WG 5G5S LT sample showed the second largest water swelling. This result was again related to the large pores observed in the sample, together with several collapsed micropores present (Figure S2). The large swelling ratios are illustrated by the increase in volume of the previous samples, WG 5G5S LT (Figure 2c) and WG 5S HT (Figure 2d). The short time $(30 \mathrm{~min})$ and long time $(24 \mathrm{~h})$ water swelling are important swelling times for sanitary and other applications such as agriculture, respectively. The WG 5S HT sample was stable and showed a sponge-like behavior even after $24 \mathrm{~h}$, and could sustain repeated manual compression for removing the water (Video S1). Thus, a sponge/elastic behavior similar to the one previously obtained with lyophilized foams can also be obtained using the extrusion technique [20,21,31]. However, when the WG 5G5S LT sample was compressed, the material did not maintain its shape to a $100 \%$ degree (Video S1). Previously, we showed that non-lyophilized WG porous materials using glutaraldehyde as protein network stabilizer were able to swell $468 \%$ in water [31]. The values reported here show approximately $50 \%$ of the maximum swelling of the previously reported values using glutaraldehyde. Although the maximum swelling ratios are lower, the combination of the commercially attractive extrusion technique and the absence of toxic crosslinking agents represents a promising continuation of studies for the production of environmentally friendly absorbent materials. 

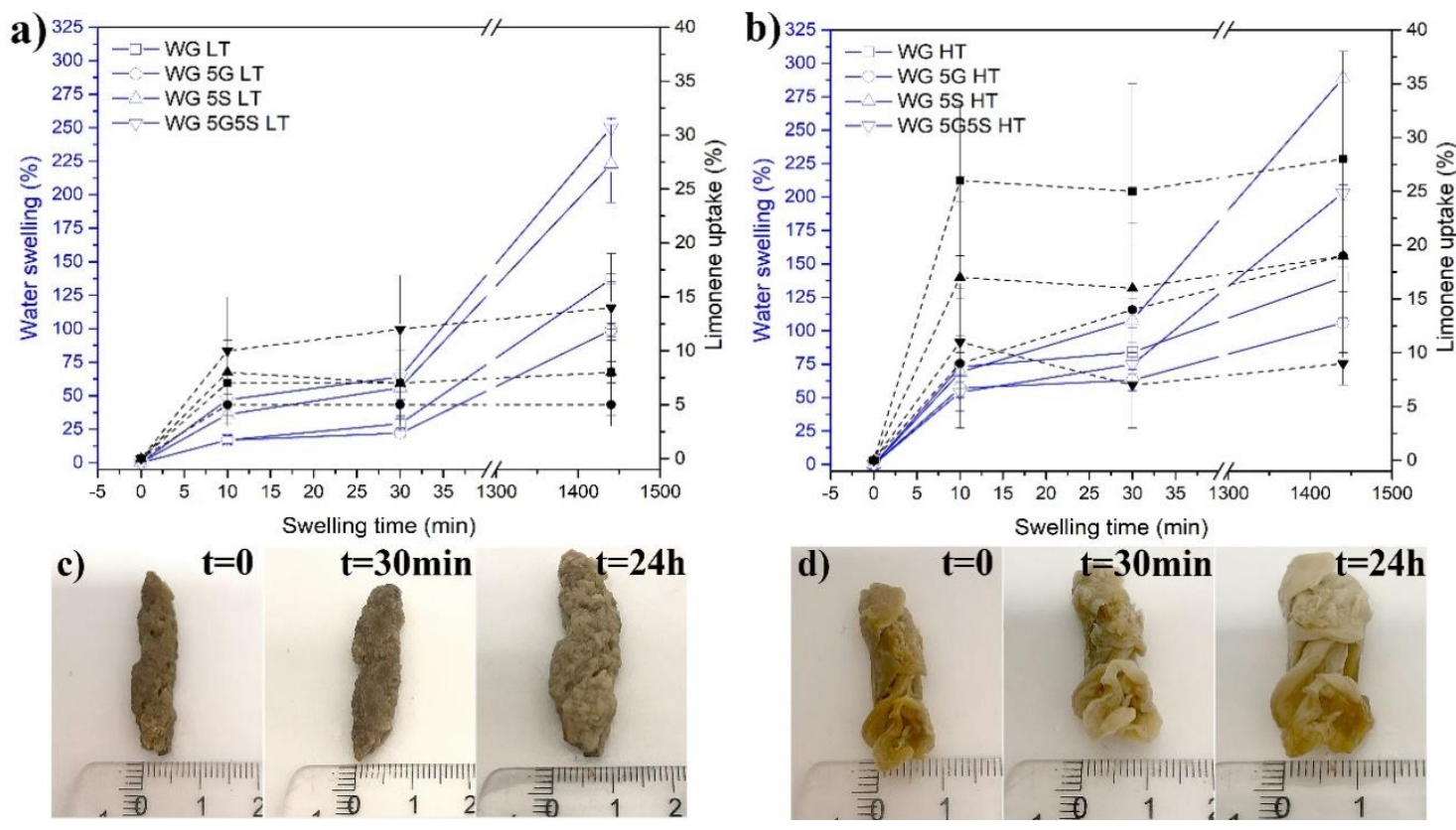

Figure 2. Liquid uptake in the different samples at low (a) and high (b) extrusion temperatures. A representative specimen of WG 5G5S LT (c) and WG 5S HT (d) after a $24 \mathrm{~h}$ swelling in water are shown. The continuous line with hollow symbols corresponds to water swelling, and the dashed lines with filled symbols correspond to limonene uptake.

Limonene was used to evaluate the non-polar liquid uptake capacity of the different samples, and all samples reached the maximum limonene uptake after $10 \mathrm{~min}$. The capillary action responsible for this rapid uptake is an important parameter for non-polar liquid superabsorbent applications. The highest limonene uptake was achieved in the WG HT sample (30\%). WG 5G LT and WG LT showed the lowest limonene uptake ( $5 \%$ and $8 \%$, respectively). The reason for the low limonene uptake for the samples was likely due to the dense skin layer observed (Figure 1a,c), which hindered and slowed the limonene (and also water) penetration into the inner part of the material. For an illustration of the rapid limonene uptake, see Video S2 where the WG HT sample was placed in contact with limonene.

The lyophilization of the WG 5G5S LT sample after being immersed $24 \mathrm{~h}$ in water revealed that the large scattered pores and the more or less solid pore walls were absent. Instead, a highly porous structure was obtained (pore size of $34 \pm 10 \mu \mathrm{m}$ ), which could be ascribed to the sublimation of the water crystals formed from freezing of the originally highly swollen cylinder. In fact, the porous microstructure resembled the structure of the originally freeze-dried reference WG foam (WG(f)) (Figure 3a), having a pore size of $27 \mu \mathrm{m}$ (Table 2). Figure 3a shows that the WG(f) foam kept approximately the same microstructure even after a second lyophilization (after being swollen in water for $24 \mathrm{~h}$, Figure 2a right). Compared to the original WG(f) foam, the WG(f) material freeze-dried twice had thicker cell walls $(>15 \mu \mathrm{m})$ and a microporosity within the cell walls. The pores in WG(f) after the second lyophilization were slightly larger than in the original foam (Table 2), here $75 \pm 46 \mu \mathrm{m}$. The newly developed porosity in WG 5G5S LT also illustrates that the water penetrated the entire cross-section of the sample homogenously (Figure 3b). 


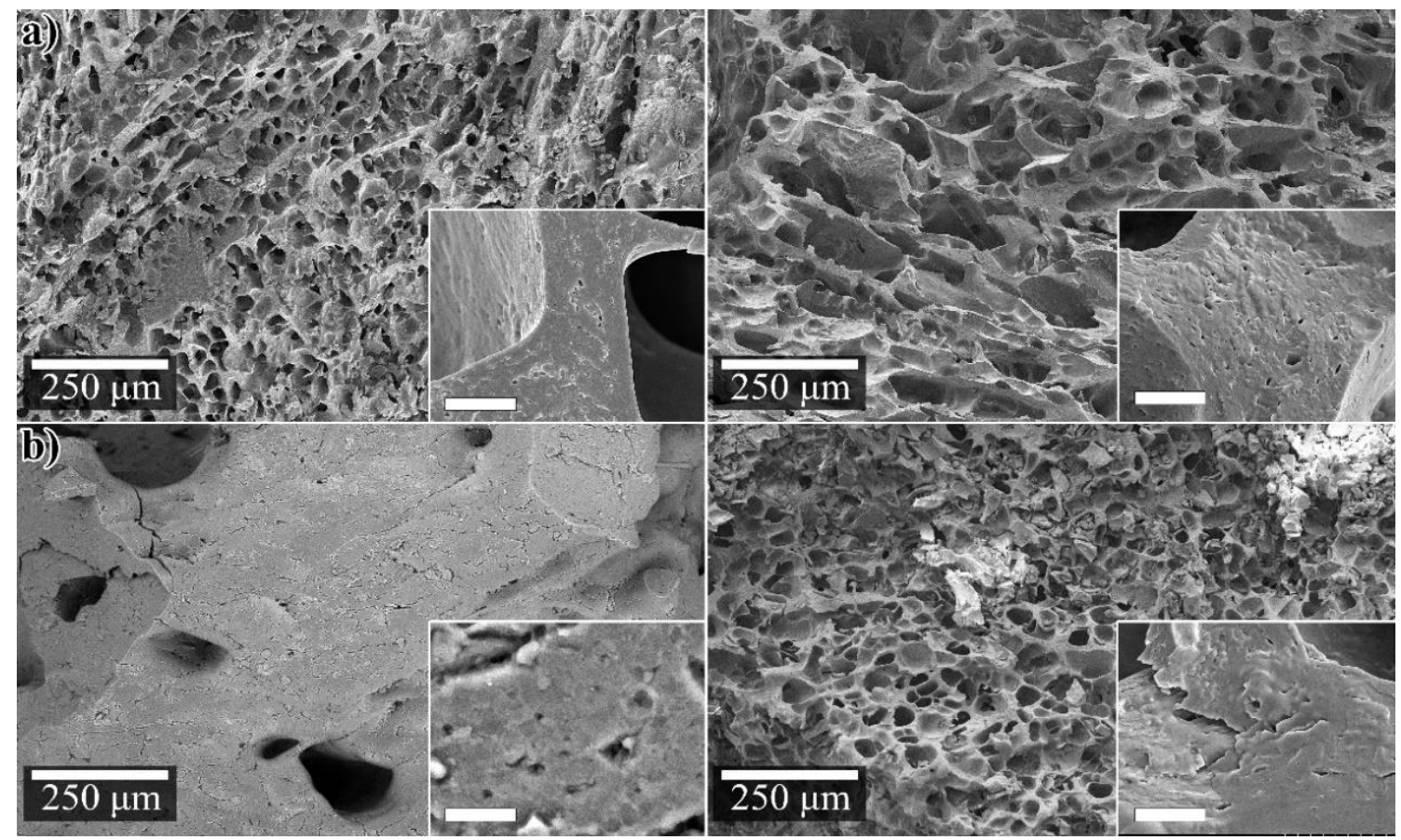

Figure 3. (a) WG(f) (left), WG(f) after 24h swelling (right); (b) WG 5G5S LT (left), after 24h swelling and lyophilized (right). The bar in the insert indicates $5 \mu \mathrm{m}$.

As previously discussed, the WG 5G LT sample consisted of a porous core structure with a denser skin, whereas the WG 5S HT cross-section revealed a dense layer having large pores that had collapsed (Figure $4 a$, Figure $4 b$, respectively). To demonstrate the effect of the water penetration within the dense layers of the latter samples after 24 water swelling, the lyophilized cross-sections of WG 5G LT and WG 5G LT are shown in Figure 4. The dense skin obtained in the extruded WG 5G LT (Figure 4a, left) changed to a highly porous skin (Figure $4 \mathrm{a}$, right). The formed porous skin showed a homogenous pore size of $30 \pm 12 \mu \mathrm{m}$ with an increase in the cross-section from approximately $0.9 \mathrm{~mm}$ to $2 \mathrm{~mm}$ after $24 \mathrm{~h}$ swelling, as a consequence of the volumetric expansion due to water swelling in the dense skin. However, the porous core observed in WG 5G LT before the water swelling (Figure 4a, left) did not show a visible change after the swelling and lyophilization (Figure $4 \mathrm{~b}$, right). This indicated that water did not swell the cell walls of the porous core in the sample. Likewise, the dense layer observed for the WG 5S HT sample also changed to a porous layer after the swelling and lyophilization of the sample (Figure $4 \mathrm{~b}$, right). To further demonstrate the effect of the dense skin in the water penetration, the WG 5G LT sample was ground to a powder and the tea-bag test was performed. The WG 5G LT powder sample had a $10 \mathrm{~min}, 30 \mathrm{~min}$ and $24 \mathrm{~h}$ water free swelling capacity (FSC) of $184 \% \pm 30 \%, 217 \% \pm 28 \%$, and $237 \% \pm 9 \%$, respectively. These values represent an increase of the short (10 $\mathrm{min}$ ) and long-term (24 h) water swelling of approximately $995 \%$ and 140\%, respectively, compared to the non-ground WG 5G LT sample. 


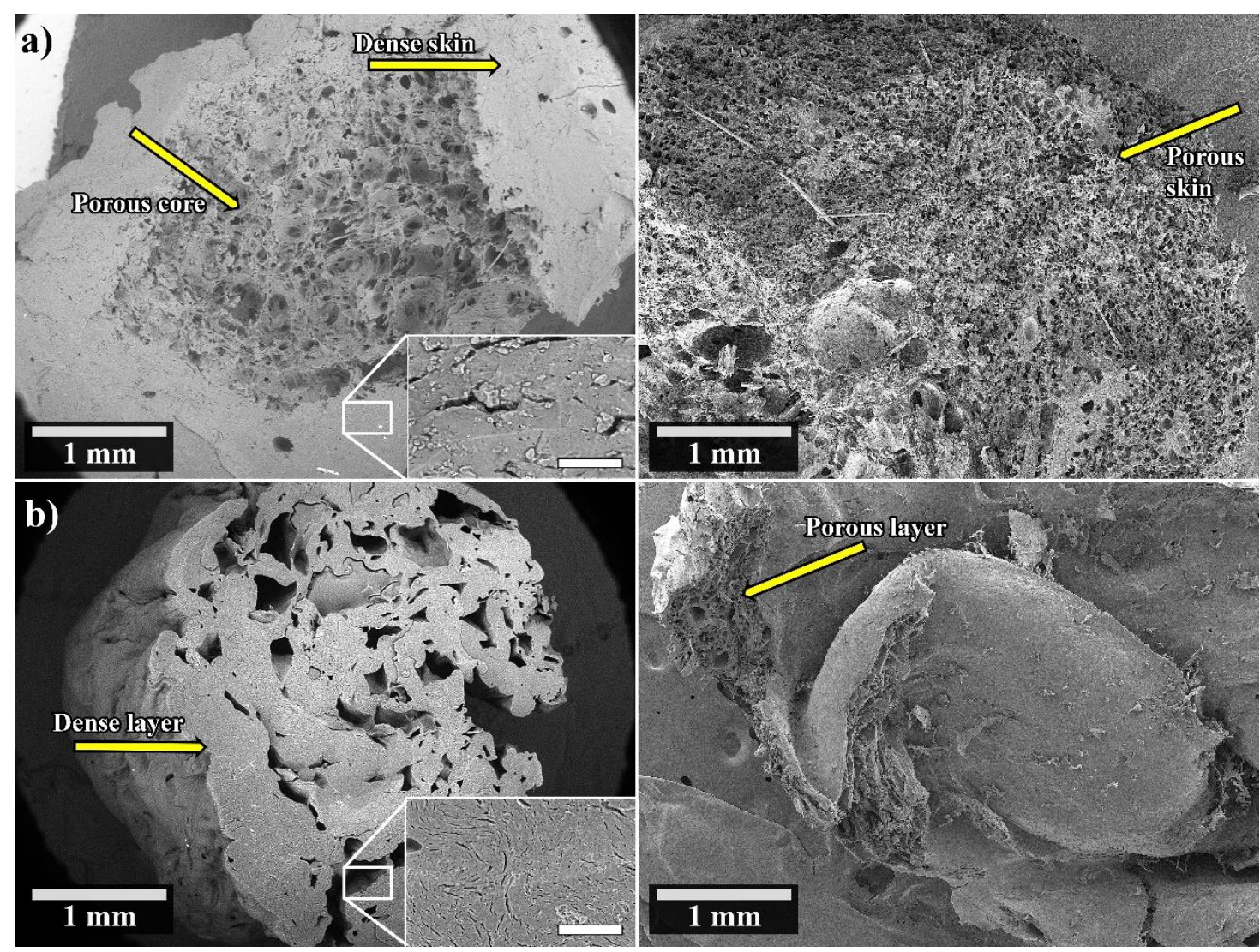

Figure 4. Cross-section of the (a) WG 5G LT (left) and WG 5G LT after $24 \mathrm{~h}$ swelling and lyophilized (right); (b) WG 5S HT (left) and WG 5S HT after $24 \mathrm{~h}$ swelling and lyophilized (right). The bar in the insert indicates $50 \mu \mathrm{m}$.

Defibrinated sheep blood absorption (30 min) in the WG 5G LT, WG 5S HT, and WG 5G5S LT samples showed an uptake capacity of $22.1 \% \pm 0.2 \%, 35.7 \% \pm 6.7 \%$, and $36.3 \% \pm 1.6 \%$, respectively. The increased blood uptake of WG 5G5S LT compared to WG 5G LT, the first having an irregular large pore structure (Figure 3b), demonstrated that the effects of the capillarity action seen in WG 5G5S LT were reduced in WG 5G LT due to its dense skin structural feature (Figure 4a). Figure 5 shows the WG 5G5S LT sample before and after the $30 \mathrm{~min}$ defibrinated sheep blood uptake test. The blood had penetrated only parts of the outer portion of the sample, and essentially not the core of the sample, which thereby decreased the blood swelling capacity of the sample. However, the considerable increase in the water swelling capacity obtained when the WG 5G LT sample was ground to powder suggests that grinding could be used as a beneficial post-process for increasing the liquid swelling of the WG extrudates and favoring the water/liquid spreading throughout the entire sample. 


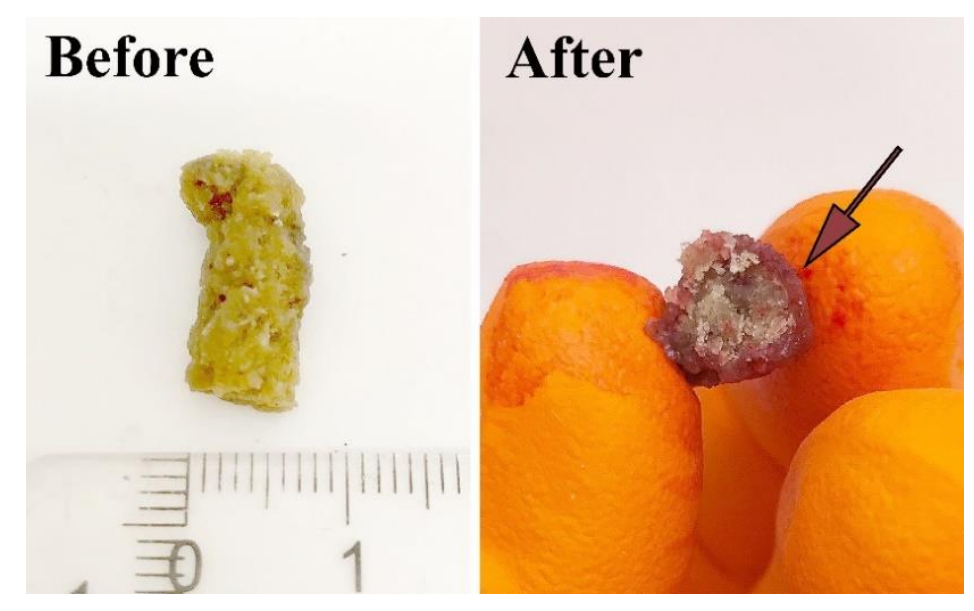

Figure 5. WG 5G5S LT before immersion in defibrinated sheep blood and a cut of the cross-section after $30 \mathrm{~min}$ immersion in the liquid.

\subsection{Protein Thermal and Structural Characteristics}

Figure 6 shows the thermal stability of the different samples produced. The onset temperature of degradation and the maximum mass loss rate of each sample are summarized in Table 3 , including the results for the TGA analysis of the as-received WG powder. The samples WG LT, WG HT, WG 5G LT, and WG 5G HT showed no significant difference in the thermal stability with respect to the onset of weight loss and the maximum mass loss rate (Table 3). However, the increase in approximately $15{ }^{\circ} \mathrm{C}$ in the maximum mass loss rate for the above-mentioned samples compared to the raw WG indicated the effect on the gluten by the thermal/alkali treatment when extruded, possibly inducing crosslinking in the protein and thereby increasing their thermal properties $[38,44,45]$. On the other hand, all the samples treated with sodium bicarbonate, namely, WG 5S LT, WG 5S HT, WG 5G5S LT and WG 5G5S HT, had a lower onset and maximum mass loss rate temperatures than the other extruded samples (Table 3). The decrease in the thermal stability of the samples where sodium bicarbonate was used suggests that the $\mathrm{NaHCO}_{3}$ could also influence the group functionality of the WG protein. This is in accordance with previous reports, where the functionalization of proteins was shown to influence the thermal behavior of the protein samples [46,47]. Additionally, the modification of the functional/charged groups in the WG can contribute to the increase in water swelling due to charge repulsion in the material [11], which is in line with the higher water swelling results obtained for WG 5G5S LT and WG 5S HT, for example (approximately $280 \%$, see Figure 2). The TGA profiles of the neat sodium bicarbonate (Figure S3) show that at $120{ }^{\circ} \mathrm{C}$ the bicarbonate starts to degrade, forming $\mathrm{CO}_{2}(\mathrm{~g})$. This again corresponds with the large porous structure obtained for WG 5S HT, as discussed previously in Section 3.1. The results also suggest the potential for future work related to the method herein suggested utilizing higher extrusion temperature for an even larger foaming effect of the $\mathrm{NaHCO}_{3}$ through its thermal degradation. 

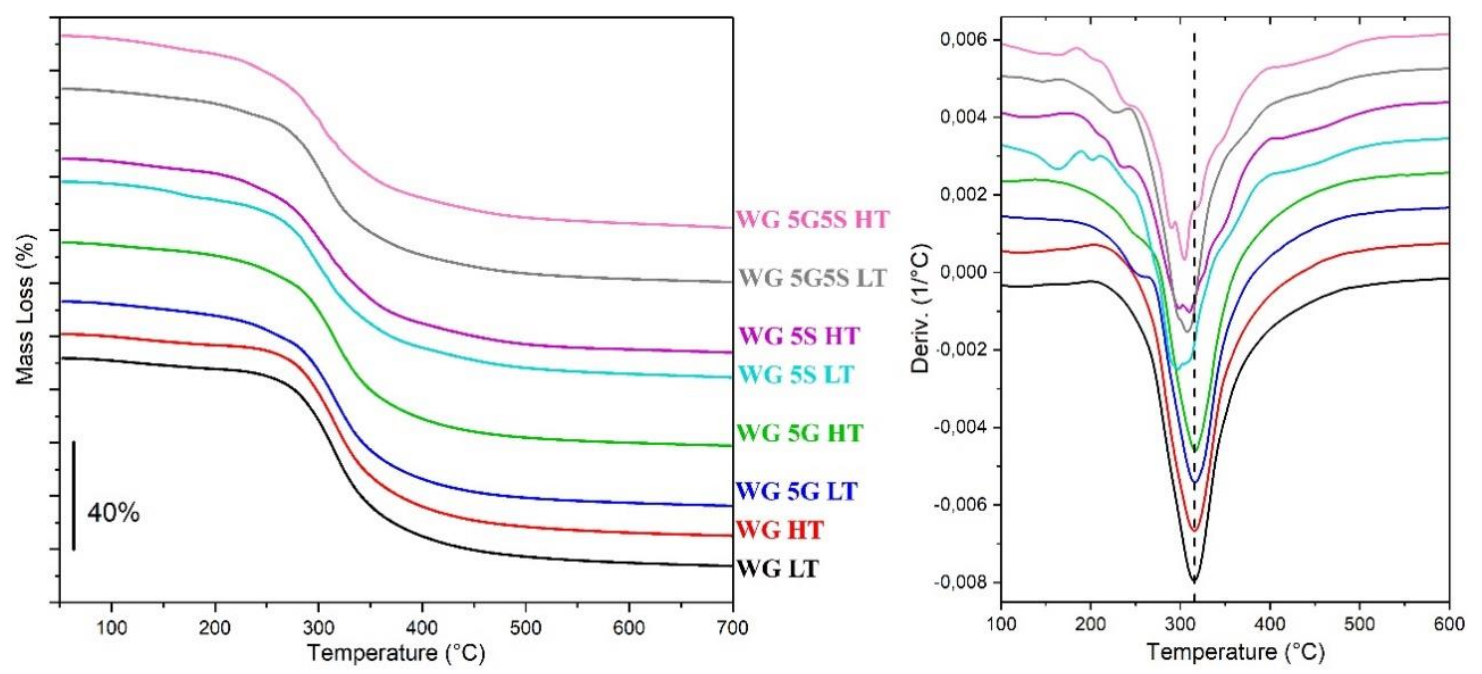

Figure 6. Thermal stability of the samples (left) and first derivative (right). The curves were stacked for clarity.

Table 3. Summary of the thermal properties obtained from the TGA curves.

\begin{tabular}{ccc}
\hline Sample & Onset Temp. $\left({ }^{\circ} \mathbf{C}\right)$ & Max. Mass Loss Rate $\left({ }^{\circ} \mathbf{C}\right)$ \\
\hline Raw WG & 274 & 302 \\
WG LT & 278 & 315 \\
WG HT & 278 & 316 \\
WG 5G LT & 276 & 316 \\
WG 5G HT & 273 & 317 \\
WG 5S LT & 269 & 298 \\
WG 5S HT & 259 & 311 \\
WG 5G5S LT & 267 & 307 \\
WG 5G5S HT & 259 & 305 \\
\hline
\end{tabular}

The FTIR amide I region of the extruded WG materials, as well as the as-received WG powder, reflects the protein secondary structure, as seen in Figure 7a. The full FTIR spectra of all samples are shown in Figure S4. Overall, all the extruded samples (with the exception of WG 5S LT) showed a change/shifting in the amide I region $\left(1680-1580 \mathrm{~cm}^{-1}\right)$ compared to the neat WG powder, indicating an increase in the content of $\beta$-sheet structure and decreased $\alpha$-helix content for the extruded samples. The largest shift and strongest peaks at lower wave numbers (below $1635 \mathrm{~cm}^{-1}$ ) corresponding to $\beta$-sheets was observed for the WG HT sample, whereas a smaller shift was apparent for WG $5 S$ LT. High temperatures are known to favor WG protein aggregation/crosslinking [48], which then influences protein thermal stability and increases the $\beta$-sheet content, as reflected in the amide I spectra (Figure 7a). On the other hand, the samples containing glycerol (both at low and high temperatures) did not display major changes in the secondary structure when compared to WG HT and WG 5S HT (Figure 7a). This agrees with the fact that glycerol acts as a protein plasticizer, increasing the mobility of the chains and reducing their inter/intra-molecular interactions $[49,50]$. 

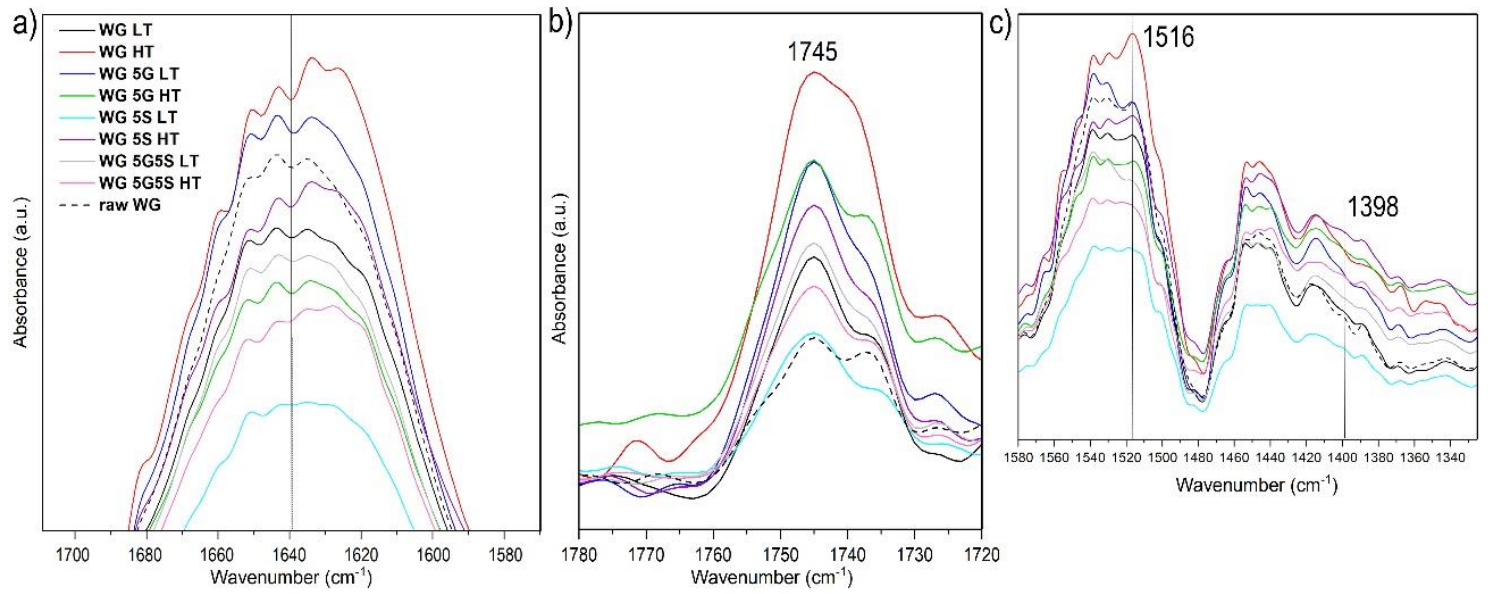

Wavenumber $\left(\mathrm{cm}^{-1}\right)$

Figure 7. FTIR of the amide I region (a), the carbonyl region (b) and $1550-1340 \mathrm{~cm}^{-1}$ region (c) for the different samples.

An increase in the carbonyl region intensity $\left(1760-1720 \mathrm{~cm}^{-1}\right)$ for all samples compared to the neat WG (except for WG 5S LT) suggests that the protein carbonyl functionality was exposed after the temperature/alkali treatments (Figure $7 \mathrm{~b}$ ). The shoulder observed at $1398 \mathrm{~cm}^{-1}$ for WG $5 S$ HT suggests that there is an increase in the carbonyl functionality in the protein coming from the formation of sodium-neutralized carboxylic acid groups (symmetric stretching) [51,52]. The results agree with the one showing that the highest water swelling was observed for the WG 5S HT sample (coupled with the large open-cell structure), thereby indicating an apparent partial functionalization of the gluten macromolecules by the sodium bicarbonate. Sodium bicarbonate as a simultaneous foaming and functionalization agent of WG materials is thus suggested as an interesting reagent for the production of extruded protein-based materials [11,14]. The functionalization of protein side-streams, such as wheat gluten (WG), has been shown to be beneficial in increasing their water swelling properties, making them more attractive as compared to the current non-sustainable synthetic SAPs [40].

\section{Conclusions}

Extruded porous wheat gluten (WG) with water, glycerol, and sodium bicarbonate as green reactants was evaluated. The wheat gluten extruded with sodium bicarbonate at $120^{\circ} \mathrm{C}$ showed a porous structure that allowed $>275 \%$ water uptake while having highly resilient properties when repeatedly compressed. The interconnected pores also allowed the WG material to take up $>20 \%$ of a non-polar liquid (limonene). Extrusion of only WG and water (1:1 ratio) at low temperature $\left(80^{\circ} \mathrm{C}\right)$ resulted in extruded materials having a porosity of approximately $36 \%$, which was located in the core of the extrudate. Thus, it was demonstrated that using the common polymer processing technique of extrusion can be foreseen as a potential technique to produce porous WG protein materials with a high swelling capacity. The results pave the way for the continuous production of sustainable and biodegradable polymers with high liquid uptake, which currently are represented by synthetic materials in the daily-care product industry.

Supplementary Materials: The following are available online at http://www.mdpi.com/2073-4360/12/2/459/s1, Figure S1: SEM micrographs of WG 5S LT (a) and WG 5S HT (b); Figure S2: SEM micrographs of WG 5G5S LT (a) and WG 5G5S HT (b); Figure S3: TGA and first derivate (inset) profiles of the sodium bicarbonate; Figure S4: Full FTIR spectra of all the samples extruded, including the as-received WG powder (raw WG); Video S1: Sponge-like effect of WG 5S HT and WG 5G5S LT after water swelling; Video S2: Rapid limonene uptake of the extruded WG samples.

Author Contributions: Conceptualization, A.J.C., E.R., M.L., W.R.N., M.S.H., and R.T.O.; Data curation, M.S.H.; Formal analysis, A.J.C.; Investigation, E.R.; Supervision, W.R.N., E.J., M.S.H., and R.T.O.; Validation, M.L.; Writing—original draft, A.J.C.; Writing—review and editing, A.J.C., W.R.N., E.J., M.S.H., and R.T.O. All authors have read and agreed to the published version of the manuscript. 
Funding: This research was funded by VINNOVA, grant number 2015-03506, in collaboration with Lantmännen ek för and Essity Hygiene \& Health AB.

Acknowledgments: The authors acknowledge Samy Gharbi for his technical support during the sample preparations. Annelie Moldin is acknowledged for her support and technical review on behalf of Lantmännen ek för. The disease vector group, SLU Alnarp, is acknowledged for proving us with the defibrinated sheep blood used. Joel Markgren is acknowledged for providing the rendered protein structures used in the Table of content graphics.

Conflicts of Interest: The authors declare no conflict of interest.

\section{References}

1. Jin, F.-L.; Zhao, M.; Park, M.; Park, S.-J. Recent Trends of Foaming in Polymer Processing: A Review. Polymers 2019, 11, 953. [CrossRef] [PubMed]

2. Khemani, K.C. Polymeric Foams: An Overview. In Polymeric Foams; American Chemical Society: Washington, DC, USA, 1997; Volume 669, pp. 1-7.

3. Paciorek-Sadowska, J.; Borowicz, M.; Czupryński, B.; Isbrandt, M. Effect of Evening Primrose Oil-Based Polyol on the Properties of Rigid Polyurethane-Polyisocyanurate Foams for Thermal Insulation. Polymers 2018, 10, 1334. [CrossRef]

4. Gama, N.V.; Ferreira, A.; Barros-Timmons, A. Polyurethane Foams: Past, Present, and Future. Materials 2018, 11, 1841. [CrossRef] [PubMed]

5. Sabbahi, A.; Vergnaud, J.M. Absorption of water by polyurethane foam. modelling and experiments. Eur. Polym. J. 1993, 29, 1243-1246. [CrossRef]

6. Atta, A.M.; Brostow, W.; Hagg Lobland, H.E.; Hasan, A.R.M.; Perez, J.M. Network and swelling parameters of cross-linked octadecylacrylate-co-acrylic acid copolymers based on divinyl benzene cross-linker. Mater. Res. Innov. 2015, 19, 459-468. [CrossRef]

7. Atta, A.M.; Brostow, W.; Hagg Lobland, H.E.; Hasan, A.-R.M.; Perez, J.M. Porous crosslinked copolymers of octadecyl acrylate with acrylic acid as sorbers for crude petroleum spills. Polym. Int. 2013, 62, 1225-1235. [CrossRef]

8. Atta, A.M.; Brostow, W.; Hagg Lobland, H.E.; Hasan, A.-R.M.; Perez, J.M. Porous polymer oil sorbents based on PET fibers with crosslinked copolymer coatings. Rsc Adv. 2013, 3, 25849-25857. [CrossRef]

9. Ahmed, E.M. Hydrogel: Preparation, characterization, and applications: A review. J. Adv. Res. 2015, 6, 105-121. [CrossRef]

10. Brandt, K.A.; Goldman, S.A.; Inglin, T.A. Hydrogel-forming polymer compositions for use in absorbent structures. U.S. Patent 4,654,039, 31 March 1987.

11. Capezza, A.J.; Newson, W.R.; Olsson, R.T.; Hedenqvist, M.S.; Johansson, E. Advances in the Use of Protein-Based Materials: Toward Sustainable Naturally Sourced Absorbent Materials. Acs Sustain. Chem. Eng. 2019, 7, 4532-4547. [CrossRef]

12. Demitri, C.; Del Sole, R.; Scalera, F.; Sannino, A.; Vasapollo, G.; Maffezzoli, A.; Ambrosio, L.; Nicolais, L. Novel superabsorbent cellulose-based hydrogels crosslinked with citric acid. J. Appl. Polym. Sci. 2008, 110, 2453-2460. [CrossRef]

13. Pourjavadi, A.; Kurdtabar, M.; Mahdavinia, G.R.; Hosseinzadeh, H. Synthesis and super-swelling behavior of a novel protein-based superabsorbent hydrogel. Polym. Bull. 2006, 57, 813-824. [CrossRef]

14. Zohuriaan-Mehr, M.J.; Kabiri, K. Superabsorbent polymer materials: A review. Iran. Polym. J. 2008, 17, 451-477.

15. Zohuriaan-Mehr, M.J.; Pourjavadi, A.; Salimi, H.; Kurdtabar, M. Protein- and homo poly(amino acid)-based hydrogels with super-swelling properties. Polym. Adv. Technol. 2009, 20, 655-671. [CrossRef]

16. Cervin, N.T.; Andersson, L.; Ng, J.B.; Olin, P.; Bergström, L.; Wågberg, L. Lightweight and Strong Cellulose Materials Made from Aqueous Foams Stabilized by Nanofibrillated Cellulose. Biomacromolecules 2013, 14, 503-511. [CrossRef] [PubMed]

17. Chen, F.; Gällstedt, M.; Olsson, R.T.; Gedde, U.W.; Hedenqvist, M.S. A novel chitosan/wheat gluten biofoam fabricated by spontaneous mixing and vacuum-drying. Rsc Adv. 2015, 5, 94191-94200. [CrossRef]

18. Svagan, A.J.; Samir, M.A.S.A.; Berglund, L.A. Biomimetic Foams of High Mechanical Performance Based on Nanostructured Cell Walls Reinforced by Native Cellulose Nanofibrils. Adv. Mater. 2008, 20, 1263-1269. [CrossRef] 
19. Wu, Q.; Andersson, R.L.; Holgate, T.; Johansson, E.; Gedde, U.W.; Olsson, R.T.; Hedenqvist, M.S. Highly porous flame-retardant and sustainable biofoams based on wheat gluten and in situ polymerized silica. J. Mater Chem. A. 2014, 2, 20996-21009. [CrossRef]

20. Wu, Q.; Yu, S.; Kollert, M.; Mtimet, M.; Roth, S.V.; Gedde, U.W.; Johansson, E.; Olsson, R.T.; Hedenqvist, M.S. Highly Absorbing Antimicrobial Biofoams Based on Wheat Gluten and Its Biohybrids. Acs Sustain. Chem. Eng. 2016, 4, 2395-2404. [CrossRef]

21. Capezza, A.J.; Wu, Q.; Newson, W.R.; Olsson, R.T.; Espuche, E.; Johansson, E.; Hedenqvist, M.S. Superabsorbent and Fully Biobased Protein Foams with a Natural Cross-Linker and Cellulose Nanofiber. Acs Omega 2019, 4, 18257-18267. [CrossRef]

22. Karlsson, K.; Nylander, F.; Lundman, M.; Berta, M.; Stading, M.; Westman, G.; Rigdahl, M. Hot-mould foaming of modified hemicelluloses and hydroxypropyl methylcellulose. J. Polym. Res. 2019, 26, 206. [CrossRef]

23. Cuadri, A.A.; Romero, A.; Bengoechea, C.; Guerrero, A. The Effect of Carboxyl Group Content on Water Uptake Capacity and Tensile Properties of Functionalized Soy Protein-Based Superabsorbent Plastics. J. Polym. Environ. 2018, 26, 2934-2944. [CrossRef]

24. Hao, A.; Geng, Y.; Xu, Q.; Lu, Z.; Yu, L. Study of different effects on foaming process of biodegradable PLA/starch composites in supercritical/compressed carbon dioxide. J. Appl. Polym. Sci. 2008, 109, 2679-2686. [CrossRef]

25. Cooper, A.I. Porous Materials and Supercritical Fluids. Adv. Mater. 2003, 15, 1049-1059. [CrossRef]

26. Quester, S.; Dahesh, M.; Strey, R. Microcellular foams made from gliadin. Colloid Polym. Sci. 2014, 292, 2385-2389. [CrossRef] [PubMed]

27. Baudron, V.; Gurikov, P.; Smirnova, I.; Whitehouse, S. Porous Starch Materials via Supercritical- and Freeze-Drying. Gels 2019, 5, 12. [CrossRef] [PubMed]

28. Lam, S.; Velikov, K.P.; Velev, O.D. Pickering stabilization of foams and emulsions with particles of biological origin. Curr. Opin. Colloid Interface 2014, 19, 490-500. [CrossRef]

29. Horozov, T.S. Foams and foam films stabilised by solid particles. Curr. Opin. Colloid Interface Sci. 2008, 13, 134-140. [CrossRef]

30. Yang, Y.; Fang, Z.; Chen, X.; Zhang, W.; Xie, Y.; Chen, Y.; Liu, Z.; Yuan, W. An Overview of Pickering Emulsions: Solid-Particle Materials, Classification, Morphology, and Applications. Front. Pharm. 2017, 8, 287. [CrossRef]

31. Alander, B.; Capezza, A.J.; Wu, Q.; Johansson, E.; Olsson, R.T.; Hedenqvist, M.S. A facile way of making inexpensive rigid and soft protein biofoams with rapid liquid absorption. Ind. Crop. Prod. 2018, 119, 41-48. [CrossRef]

32. Wieser, H. Chemistry of gluten proteins. Food Microbiol. 2007, 24, 115-119. [CrossRef]

33. Wu, Q.; Rabu, J.; Goulin, K.; Sainlaud, C.; Chen, F.; Johansson, E.; Olsson, R.T.; Hedenqvist, M.S. Flexible strength-improved and crack-resistant biocomposites based on plasticised wheat gluten reinforced with a flax-fibre-weave. Compos. Part. A-Appl. Sci. 2017, 94, 61-69. [CrossRef]

34. Shewry, P.R.; Halford, N.G.; Belton, P.S.; Tatham, A.S. The structure and properties of gluten: An elastic protein from wheat grain. Philos. Trans. Roy. Soc. B 2002, 357, 133-142. [CrossRef] [PubMed]

35. Deng, Y.; Achten, W.M.J.; Van Acker, K.; Duflou, J.R. Life cycle assessment of wheat gluten powder and derived packaging film. Biofuel. Bioprod. Bior. 2013, 7, 429-458. [CrossRef]

36. Maier, C.; Calafut, T. (Eds.) Extrusion. In Polypropylene; William Andrew Publishing: Norwich, NY, USA, 1998; pp. 205-221. [CrossRef]

37. Wagner, J.R.; Mount, E.M.; Giles, H.F. (Eds.) Extrusion Process. In Extrusion, 2nd ed.; William Andrew Publishing: Oxford, UK, 2014; pp. 3-11. [CrossRef]

38. Olabarrieta, I.; Cho, S.-W.; Gällstedt, M.; Sarasua, J.-R.; Johansson, E.; Hedenqvist, M.S. Aging Properties of Films of Plasticized Vital Wheat Gluten Cast from Acidic and Basic Solutions. Biomacromolecules. 2006, 7, 1657-1664. [CrossRef] [PubMed]

39. ISO. Test methods for nonwovens. In Part 6: Absorption; ISO: Geneva, Switzerland, 2016; Volume 59.080.30, p. 9.

40. Capezza, A.J.; Lundman, M.; Olsson, R.T.; Newson, W.R.; Hedenqvist, M.S.; Johansson, E. Carboxylated Wheat Gluten Proteins: A Green Solution for Production of Sustainable Superabsorbent Materials. Biomacromolecules 2020. [CrossRef] [PubMed] 
41. Cho, S.W.; Gällstedt, M.; Johansson, E.; Hedenqvist, M.S. Injection-molded nanocomposites and materials based on wheat gluten. Int. J. Biol. Macromol. 2011, 48, 146-152. [CrossRef]

42. Rueden, C.T.; Schindelin, J.; Hiner, M.C.; DeZonia, B.E.; Walter, A.E.; Arena, E.T.; Eliceiri, K.W. ImageJ2: ImageJ for the next generation of scientific image data. BMC Bioinform. 2017, 18, 529. [CrossRef]

43. Hartman, M.; Svoboda, K.; Pohořelý, M.; Šyc, M. Thermal Decomposition of Sodium Hydrogen Carbonate and Textural Features of Its Calcines. Ind. Eng. Chem. Res. 2013, 52, 10619-10626. [CrossRef]

44. Johansson, E.; Malik, A.H.; Hussain, A.; Rasheed, F.; Newson, W.R.; Plivelic, T.; Hedenqvist, M.S.; Gällstedt, M.; Kuktaite, R. Wheat Gluten Polymer Structures: The Impact of Genotype, Environment, and Processing on Their Functionality in Various Applications. Cereal Chem. 2013, 90, 367-376. [CrossRef]

45. Muneer, F.; Johansson, E.; Hedenqvist, M.S.; Plivelic, T.S.; Kuktaite, R. Impact of pH Modification on Protein Polymerization and Structure-Function Relationships in Potato Protein and Wheat Gluten Composites. Int. J. Mol. Sci. 2018, 20, 58. [CrossRef]

46. Capezza, A.J.; Glad, D.; Özeren, H.D.; Newson, W.R.; Olsson, R.T.; Johansson, E.; Hedenqvist, M.S. Novel Sustainable Superabsorbents: A One-Pot Method for Functionalization of Side-Stream Potato Proteins. Acs Sustain. Chem. Eng. 2019, 7, 17845-17854. [CrossRef]

47. Chiou, B.S.; Jafri, H.; Cao, T.; Robertson, G.H.; Gregorski, K.S.; Imam, S.H.; Glenn, G.M.; Orts, W.J. Modification of wheat gluten with citric acid to produce superabsorbent materials. J. Appl. Polym. Sci. 2013, 129, 3192-3197. [CrossRef]

48. Newson, W.R.; Rasheed, F.; Kuktaite, R.; Hedenqvist, M.S.; Gallstedt, M.; Plivelic, T.S.; Johansson, E. Commercial potato protein concentrate as a novel source for thermoformed bio-based plastic films with unusual polymerisation and tensile properties. Rsc Adv. 2015, 5, 32217-32226. [CrossRef]

49. Vieira, M.G.A.; da Silva, M.A.; dos Santos, L.O.; Beppu, M.M. Natural-based plasticizers and biopolymer films: A review. Eur. Polym. J. 2011, 47, 254-263. [CrossRef]

50. Gontard, N.; Guilbert, S.; Cuq, J.-L. Water and Glycerol as Plasticizers Affect Mechanical and Water Vapor Barrier Properties of an Edible Wheat Gluten Film. J. Food. Sci. 1993, 58, 206-211. [CrossRef]

51. Max, J.-J.; Chapados, C. Infrared Spectroscopy of Aqueous Carboxylic Acids: Comparison between Different Acids and Their Salts. J. Phys. Chem. A 2004, 108, 3324-3337. [CrossRef]

52. Nájera, J.J.; Horn, A.B. Infrared spectroscopic study of the effect of oleic acid on the deliquescence behaviour of ammonium sulfate aerosol particles. Phys. Chem. Chem. Phys. 2009, 11, 483-494. [CrossRef] 